\title{
A chegada de novos agentes econômicos e a reestruturação do espaço urbano em Queimados - Rio de Janeiro
}

The arrival of new economic actors and the restructuring of the urban space in Queimados - Rio de Janeiro

L'arrivée de nouveaux acteurs économiques et la restructuration de l'espace urbain à Queimados - Rio de Janeiro

La llegada de nuevos actores económicos y la reestructuración del espacio urbano en Queimados - Río de Janeiro

\section{Marcelo Loura de Morais}

\section{(2) OpenEdition}

Journals

Edição electrónica

URL: http://journals.openedition.org/espacoeconomia/2147

DOI: $10.4000 /$ espacoeconomia.2147

ISSN: 2317-7837

\section{Editora}

Núcleo de Pesquisa Espaço \& Economia

Refêrencia eletrónica

Marcelo Loura de Morais, « A chegada de novos agentes econômicos e a reestruturação do espaço urbano em Queimados - Rio de Janeiro », Espaço e Economia [Online], 8 | 2016, posto online no dia 23 setembro 2016, consultado o 30 abril 2019. URL : http://journals.openedition.org/ espacoeconomia/2147; DOI : 10.4000/espacoeconomia.2147

Este documento foi criado de forma automática no dia 30 Abril 2019.

(c) NUPEE 


\section{A chegada de novos agentes econômicos e a reestruturação do espaço urbano em Queimados - Rio de Janeiro}

The arrival of new economic actors and the restructuring of the urban space in Queimados - Rio de Janeiro

L'arrivée de nouveaux acteurs économiques et la restructuration de l'espace urbain à Queimados - Rio de Janeiro

La llegada de nuevos actores económicos y la reestructuración del espacio urbano en Queimados - Río de Janeiro

Marcelo Loura de Morais

Dizem as más línguas que ele até trabalha
Mora lá longe e chacoalha
Num trem da Central (...)

\section{Introdução}

1 Lima Barreto (s/d, p. 80 e 81), no início do século XX, ao descrever a paisagem urbana carioca $^{1}$ define que o "subúrbio é o 'refúgio dos infelizes', o lugar da "pobreza e do abandono do poder público", e que, cotidianamente, nas primeiras horas da manhã "as estações se enchem e os trens descem cheios. Mais cheios, porém, descem os que vêm do limite do Distrito com o Estado do Rio", e "o interior dos carros está apinhado e os vãos entre eles como que trazem quase a metade da lotação de um deles". Este relato bem consistente retrata o papel que coube à Baixada Fluminense durante a expansão urbana carioca no século XX: o de moradia da classe trabalhadora nas cidades-dormitórios.

2 A expansão urbana se deu "no balanço do trem" e a expansão da malha ferroviária da Estrada de Ferro Central Brasil foi a grande indutora de núcleos habitacionais pela 
periferia metropolitana. As terras da área que até então cumpriam uma função essencialmente agrária ou funcionavam somente como reserva de valor fundiário são parceladas e vendidas e o loteamento popular junto à autoconstrução tornam-se a "solução" para a questão da habitação popular (SIMÕES, 2006; 2011), levando-se em conta o encarecimento do valor da terra urbana próximo à área central.

3 Se a expansão dos loteamentos e da classe trabalhadora acompanhou a disposição da linha férrea, a expansão dos estabelecimentos industriais margeou a malha rodoviária. A abertura da Avenida Brasil (1946) e a inauguração da Rodovia Presidente Dutra (1952) foram essenciais para este processo. Terrenos próximos a estas rodovias sofreram intensa valorização e se tornaram áreas que não fizeram parte do processo de parcelamento e loteamento, foram reservadas exclusivamente para a construção de galpões industriais, principalmente no caso da Via Dutra (SIMÕES, 2011; FURLANETTO et al., 1987).

4 A chegada da indústria na Baixada Fluminense alterou a estrutura espacial e transformou estas "cidades dormitórios" em localidades economicamente dinâmicas, fazendo com que alguns centros regionais se consolidassem, como Nova Iguaçu (polo terciário) e Duque de Caxias (polo petroquímico) (OLIVEIRA, RODRIGUES, 2009; SIMÕES, 2006), e ainda com que outros municípios menores recém-emancipados aumentassem sua importância na produção industrial do Estado do Rio de Janeiro. O espaço geográfico da Baixada foi transformado profundamente, pois observamos que a "cidade perfume" dos laranjais de outrora [Nova Iguaçu] é um distante e saudoso passado² (HENRIQUE e COSTA, 2014).

Escolhemos metodologicamente Queimados como recorte geográfico com a finalidade de compreender com maior clareza estes processos em curso. Este município emancipado em 1991, localizado a aproximadamente $70 \mathrm{~km}$ de distância da capital, possui porte mediano, com uma população estimada 143.632 habitantes e uma extensão territorial de $75.695 \mathrm{Km}^{2}$ (IBGE CIDADES), e se transformou em uma "cidade-modelo" elogiada por órgãos representativos da classe industrial, como a FIRJAN, e pela "mídia especializada", consolidando-se como símbolo da "Nova Baixada". O município que ao se emancipar enfrentava dificuldades orçamentárias e contava com apenas oito secretarias (HENRIQUE e COSTA, 2014, p. 27) atualmente tem um orçamento anual de 450 milhões de reais ${ }^{3}$.

6 Essas transformações geram uma profunda recontextualização do espaço urbano, onde a cidade caracterizada historicamente como uma "periferia marginalizada", carente de infraestrutura e que comumente apresentou uma relativa "homogeneização social por baixo" com um elevado fluxo de migração pendular se transformou. As expressões de centralidade de seu núcleo comercial foram reforçadas ao se consolidarem novos espaços de consumo elitizados e ao chegarem grandes redes de lojas e de franquias ${ }^{4}$. Avaliar tais modificações é o objetivo central deste artigo.

\section{Baixada Fluminense ${ }^{5:}$ um "distante que é perto"}

7 Na década de 1990 o processo de inserção competitiva do território brasileiro na economia globalizada se intensificou. A Baixada Fluminense, neste período, passou por significativas modificações em sua rede logística e de transporte - a duplicação da Rodovia RJ- 109 e construção do Arco Metropolitano são os principais exemplos (PEREIRA, 2013) e aconteceram seguidas emancipações e reestruturações dos poderes políticos locais em busca de mais recursos e autonomia (SIMÕES, 2006), que proporcionou a constituição de novas cidades como Queimados (em 1991), Japeri (também em 1991), 
Belford Roxo (em 1993), Seropédica (em 1995) e Mesquita (no ano de 2000). Houve, destarte, o surgimento de novas bases produtivas e novos empreendimentos, além da reativação de alguns complexos industriais previamente estabelecidos - REDUC e Fábrica Nacional de Motores, em Duque de Caxias, Bayer e seu complexo químico-farmacêutico, em Belford Roxo, além da revitalização e reestruturação do porto de Sepetiba-Itaguaí (OLIVEIRA, ROCHA, 2010; 2013).

8 Segundo Rocha e Oliveira (2010, p.8), esta nova funcionalidade da região, corresponde a "própria demanda da produção industrial por mais espaços e a um menor custo que fosse viável a sua instalação, o que levará a incorporar os espaços próximos da metrópole". Dessa forma, a Baixada pode ser definida como um "distante que é perto", ou seja, uma localidade longe o suficiente das aglomerações urbanas que geram deseconomias externas, mas ainda, perto o suficiente de dois grandes mercados consumidores - Grande Rio e a Grande São Paulo.

Oliveira $(2009$, p. 8$)$ afirma que vem acontecendo "mudanças no ordenamento territorial do Rio de Janeiro" e que "essas mudanças se manifestam, em primeiro lugar, por meio do estabelecimento de novas centralidades urbanas, integrando os espaços antes tidos como periféricos"; ou seja, na metrópole carioca, que foi historicamente conhecida por polarizar toda a economia fluminense e concentrar significativamente a oferta de empregos e serviços, o dito "núcleo hipertrofiado" (ABREU, 2013, p. 17), vive um incipiente processo de descentralização produtiva, aumentando a importância relativa de núcleos urbanos outrora secundários.

Oliveira e Rodrigues (2009) confirmam a potencialidade logística da região para ascender na geografia econômica fluminense:

A região (Baixada), como visto, possui papel decisivo na economia do Rio de Janeiro e será fortemente afetada nos próximos anos por um conjunto de projetos de infraestrutura que consolidarão mudanças na estrutura produtiva do estado, tais como a expansão do porto de Sepetiba, a instalação de novas siderúrgicas em Santa Cruz e Itaguaí, o complexo gás-químico de Duque de Caxias e o próprio anel rodoviário que reestruturará integralmente o processo de circulação de pessoas e bens (OLIVEIRA, RODRIGUES, 2009, p. 137).

11 A região possui, portanto, um "papel decisivo na economia do Rio de Janeiro" e sua localização privilegiada e a disponibilidade de amplos terrenos nas margens da rodovia atraem investimentos industriais que remodelam a estrutura produtiva, reestruturando o processo de circulação de pessoas e bens.

Silva (2012, p. 126), ao realizar um levantamento dos investimentos produtivos industriais no estado do Rio de Janeiro, constata que o fortalecimento da Baixada Fluminense no cenário nacional decorre de um certo "espraiamento do crescimento industrial em direção a regiões que apresentem menores custos mentropolitanos e proximidade com centros consumidores" e que nesta região a centralidade dos investimentos têm se mantido em Duque de Caxias e Queimados, sendo que a abertura das novas plantas fabris são de setores como o metalúrgico, químico e farmacêutico principalmente. Na tabela a seguir, nota-se como é significativa a quantidade de investimentos industriais nesta região em um período mais recente.

Tabela 1. Investimentos industriais em Queimados e Duque de Caxias (1996- 2006)

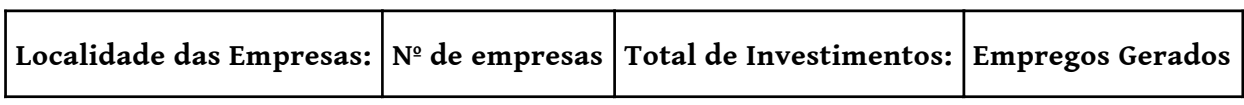




\begin{tabular}{|l|l|l|l|}
\hline Duque de Caxias & 25 & 1.580 .749 & 5.089 \\
\hline Queimados & 18 & 210.039 & 1.494 \\
\hline TOTAL & 43 & 1.790 .788 & 6.583 \\
\hline
\end{tabular}

Fonte: Organização própria. Adaptado de Silva, 2012, anexos

13 Essa atratividade exercida pela zona periférica redefine a economia fluminense descentralizando a produção industrial. No gráfico a seguir, observa-se a participação percentual no PIB industrial do estado e é possível notar essa tendência, onde a cidade do Rio de Janeiro perde importância enquanto a Baixada ganha significância em termos comparativos (Gráfico 1):

GRÁFICO 1. Participação (\%) no PIB industrial do estado do Rio de Janeiro - Região Metropolitana (RM), cidade do Rio de Janeiro e Baixada Fluminense

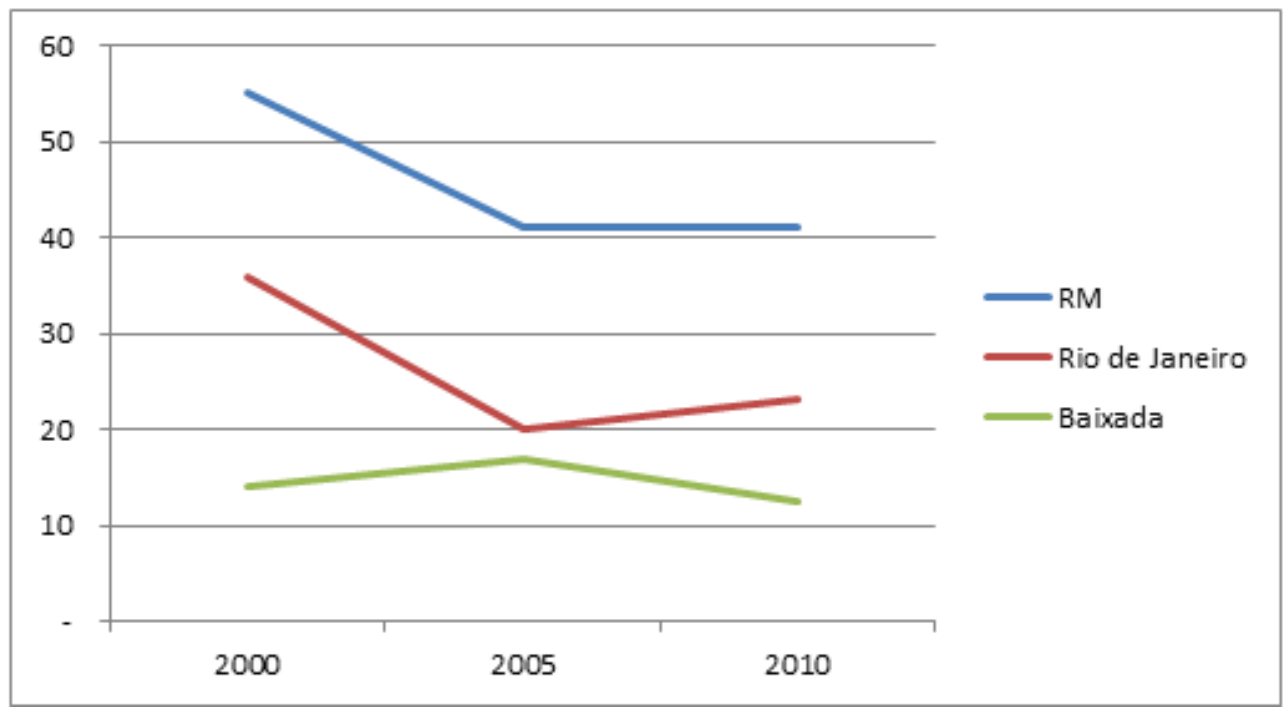

Fonte: Anuário Estatístico 2013, Fundação Ceperj. (Organização própria)

14 A perda de participação da Região metropolitana na composição total do PIB estadual se dá principalmente devido ao aumento da importância do complexo petrolífero instalado no Norte Fluminense, e a diminuição da participação da cidade do Rio de Janeiro no PIB industrial se deve justamente aos fatores de repulsão das áreas centrais e suas deseconomias externas (CORRÊA, 1989).

\section{De "cidade dormitório" a "lugar do trabalho"...}

Desde sua emancipação, uma das principais preocupações das administrações municipais de Queimados foi superar o estigma de 'cidade dormitório (HENRIQUE e COSTA, 2014). Criar oportunidades de trabalho e gerar uma sinergia local era a principal demanda da população local na luta pela emancipação. No último censo demográfico do IBGE realizado em 2010, portanto, vinte anos após a emancipação - os dados sobre migração pendular revelaram que $53 \%$ da população queimadense trabalhava em outro município. Aparentemente este número poderia demonstrar certa estagnação já que mais da metade 
da população economicamente ativa necessitava sair diariamente em busca de ocupação; contudo, quando detalhamos os dados de deslocamento separando-os por ocupação percebemos algumas tendências interessantes, conforme pode ser visto no gráfico a seguir.

Gráfico 2: Queimados (RJ) - Número de pessoas que trabalham no próprio município ou em outro município

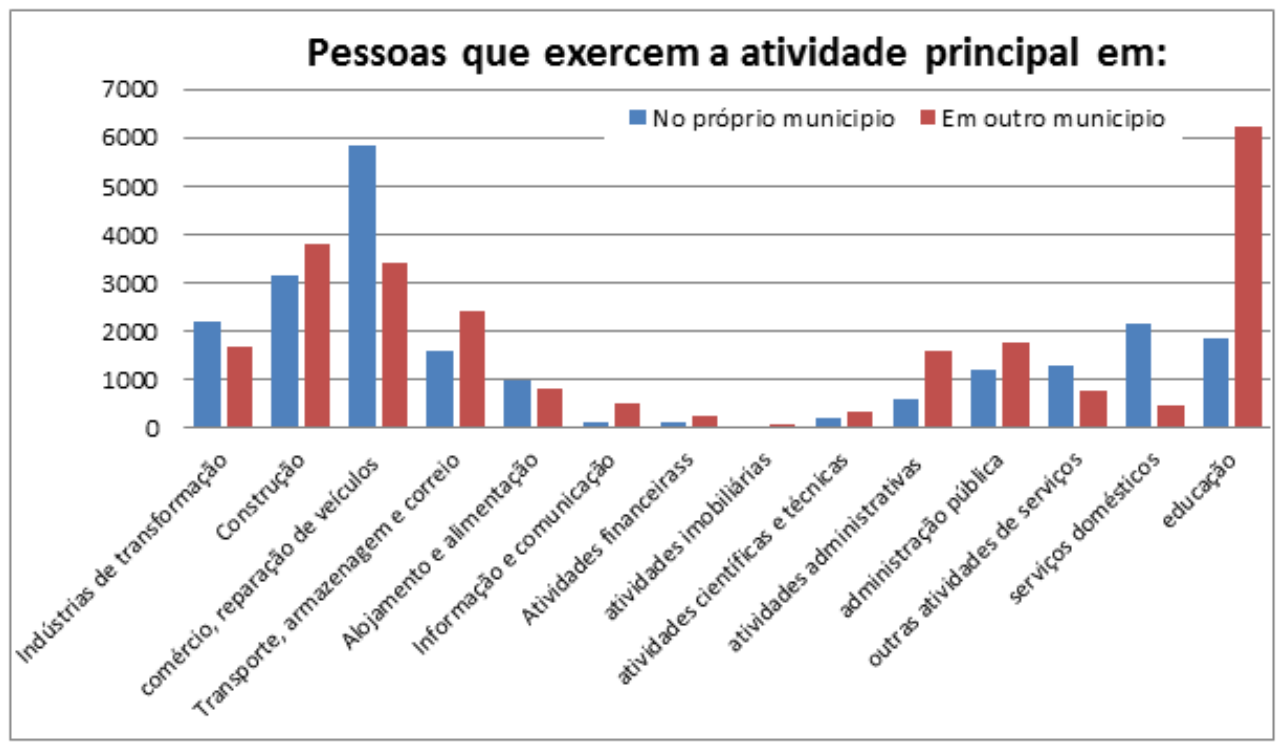

Fonte: IBGE, 2010. (Organização própria)

Em alguns setores como na indústria da transformação e no comércio o número de pessoas que trabalha no próprio município é maior, enquanto em praticamente todos os outros setores a diferença é pequena. $O$ único setor em que realmente existe uma grande diferença entre as duas variáveis é na educação, que se se explica pelo déficit histórico de presença de unidades escolares no município ${ }^{6}$.

Levando-se em conta estes números não é possível mais sustentar a tese de cidadesdormitório. Logicamente que Nova Iguaçu ${ }^{7}$ e a capital carioca ainda exercem substancial influência na cidade, mas a capacidade destes investimentos industriais em gerar ofertas de trabalho fez diminuir o fluxo cotidiano 'Baixada-Rio-Baixada'. Se esta tendência se mantiver e se o número de ofertas de trabalho se ampliar, poderemos observar nos próximos anos uma inversão histórica com o número de ocupados no interior do município tornando-se majoritário. Seria definitivamente o esgotamento da categoria "cidade dormitório" na realidade metropolitana fluminense.

Comumente retratada como o lugar das ausências, a periferia - ou a "cidade ilegal" (Maricato, s/d) - é o lugar dos loteamentos irregulares, normalmente ocupados a partir da implantação por intermédio da iniciativa privada com o intento de extrair o máximo de lucro. Assim, tais agentes não se preocupam com o "tamanho mínimo dos lotes, a largura mínima das vias, a incorporação de infraestruturas mínimas e etc." (SPOSITO, 2004, p. 283), uma vez que tais realidades são caracterizadas historicamente pela distância dos mercados de trabalho e pela homogeneidade social. Esta "periferia popular" dos loteamentos populares rotineiramente se transformou na solução capitalista encontrada para a questão da moradia, já que os custos da habitação são "externalizados" através da autoconstrução. 

quando olhamos para a Baixada e para Queimados. 0 número de empregos formais no período de 2007 a 2012 saltou de 10.148 para 26.209 , um crescimento de $158 \%$, o maior de toda região metropolitana (CEPERJ, 2013). Essas mudanças foram identificadas por Lago (2007) ao indicar a periferia como "lugar de trabalho" e demonstrar que estes processos intensificam a heterogeneidade sócio-ocupacional dos moradores, criando uma classe ocupacional de padrão médio e médio-superior.

Furlanetto et al. (1987, p.37), ao analisar a evolução urbana de Nova Iguaçu na década de 1980, constata a o surgimento de "bairros de classe média-alta com residências unifamiliares, ocupando bons e amplos terrenos com jardins, em ruas arborizadas e com boa pavimentação." Em algumas localidades mais valorizadas do município, como veremos adiante, este processo está em seu inicio na cidade de Queimados.

\section{... e agora "lugar do consumo"}

21 A cidade é um espaço articulado e fragmentado, ao mesmo tempo reflexo e condicionante social; é o lugar onde as classes sociais vivem e se reproduzem (CORRÊA, 1989, p.11), um produto social que emerge da prática social deliberada (SOJA, 1989, p. 102), uma "expressão concreta de cada conjunto histórico no qual uma sociedade se especifica" (CASTELLS, 1983, p. 146).

Sposito (2004, p. 311) define estrutura urbana como "a forma como se encontram dispostos e se articulam os usos do solo, num dado momento do contínuo processo de estruturação dos espaços da cidade", ou seja, a "forma como está organizado o espaço de uma cidade". Apesar disso, é preciso levar em conta que este espaço está sempre sofrendo constantes transformações, se desestruturando e se estruturando continuamente em "um processo contínuo, múltiplo e contraditório" - por isso a presença do sufixo ação no termo estrutura, compondo a "estruturação do espaço urbano".

A expressão reestruturação, contudo, faz referência a um processo mais profundo, "um conjunto de mudanças que orienta os processos de estruturação urbana das cidades", (SPOSITO, 2004), uma "ruptura nas tendências seculares e de uma mudança em direção a uma ordem e configuração significativamente diferentes" (SOJA, 1988, p.193). Sendo que "cada momento econômico gera uma expressiva recontextualização da espacialidade da vida social" (SOJA, 1988, p. 210).

O processo de industrialização da Baixada Fluminense e o novo momento econômico da região produz novas espacialidades que rompem com a estrutura tradicionalmente atribuída à periferia, em que "o crescimento em larga escala de áreas industriais, comerciais e de serviços que geraram empregos e, consequentemente, áreas residenciais diferenciadas que produzem uma "heterogeneização da periferia"' (FURLANETTO et. al., 1987, p. 31).

Em uma comparação entre os censos demográficos de 2000 e 2010 (consultar Tabela 2), é possível perceber essa tendência a uma transformação no perfil sócio-ocupacional.

Tabela 2: Queimados (RJ) - Domicílios particulares por faixas de renda8

\begin{tabular}{|l|l|l|}
\hline \multicolumn{2}{|l|}{ Domicílios particulares permanentes } \\
\hline & & Classes de salário mínimo (\%) \\
& Ano & Total
\end{tabular}




\begin{tabular}{|l|l|l|l|l|l|l|}
\cline { 3 - 6 } & & Até 1 & De 1 a 2 & De 2 a 3 & Mais de 3 \\
\hline 2000 & 33352 & 53,9 & 27,6 & 8,8 & 9,7 \\
\hline \multicolumn{5}{|c|}{} \\
\hline & & Até 1 & De 1 a 2 & De 2 a 5 & mais de 5 \\
\hline 2010 & $\mathbf{4 2 2 3 0}$ & 22 & 26 & 39 & 13 \\
\hline
\end{tabular}

Fonte: Censo demográfico do IBGE (2000 e 2010)

Nota-se um crescimento significativo na classe de renda recebedora de dois a cinco salários mínimos, e uma presença significativa (13\%) de domicílios com mais de cinco salários mínimos. Este processo de elevação da "renda média" fica mais evidente ao compararmos o município com os demais da Baixada, como podermos observar no mapa a seguir que apresenta as faixas de rendimento médio mensal em nosso recorte espacial investigado (Figura 1). Afinal, a chegada das indústrias e a ampliação do mercado de trabalho local representaram a criação de uma camada com maior poder aquisitivo e maior poder de consumo, fazendo com que a cidade se tornasse mais atrativa para investimentos imobiliários, comerciais e gerando uma qualificação na oferta de serviços, o que reforçou uma relativa centralidade do município. A concentração desta "classe de maior poder aquisitivo" se dá preferencialmente próxima ao centro urbano, pois isto garante aos seus moradores o acesso privilegiado à infraestrutura que o núcleo passa a possuir, como podemos observar no mapa e na figura 1 a seguir organizados a partir dos setores censitários do IBGE.

Mapa 1: Queimados: algumas características
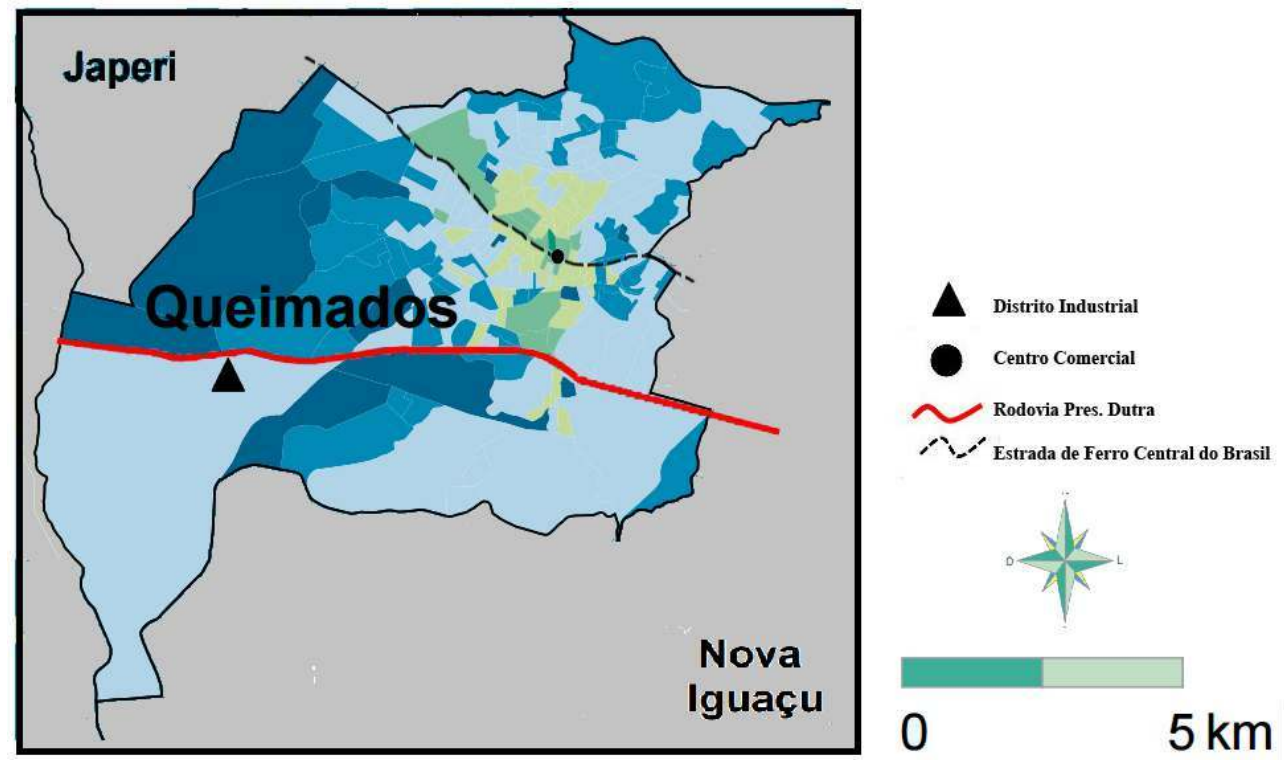

Fonte: Setores censitários IBGE 
Figura 1. Rendimento mensal domiciliar per capita por setores censitários

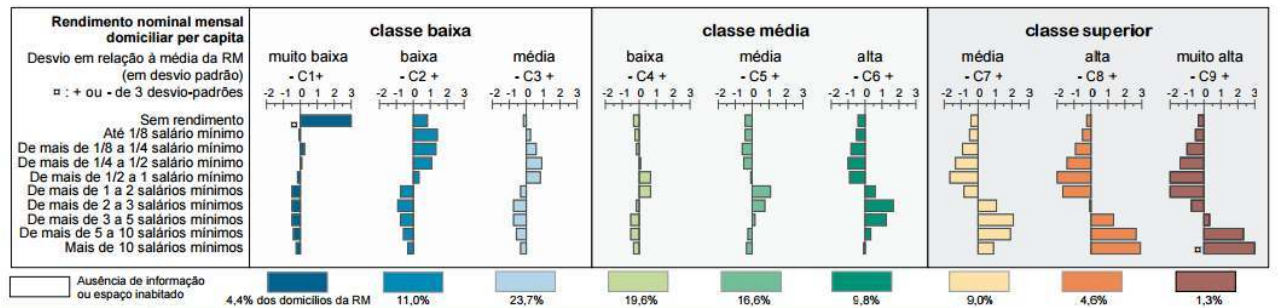

Fonte: Jacob, Hees, Waniez, 2014 (adaptado)

Bem próximo ao núcleo é possível perceber a presença de uma classe média alta (C6) e em seu entorno algumas faixas de rendimento $\mathrm{C} 5$ e $\mathrm{C} 4$ (média e baixa). É buscando esse novo público consumidor que novos empreendimentos imobiliários chegam à cidade. Da mesma maneira, rompendo com o padrão histórico de ocupação baseado em loteamentos populares, uma oferta de residência de elevado padrão surge e reconfigura a paisagem da periferia.

Em um levantamento preliminar ${ }^{9}$ encontramos ofertas de residências de padrão médio a elevado em uma das áreas mais valorizadas da cidade, próximo ao centro, com o preço do metro quadrado a aproximadamente a $R \$ 3.139,00$. Para efeito de comparação o centro de Nova Iguaçu está com o metro quadrado custando em média R\$5.687,00. Nas imagens a seguir (fotos tiradas em trabalho de campo, realizado no dia 28 de novembro de 2015), podemos observar uma propaganda destes novos empreendimentos anunciando as "últimas unidades" e também a fachada residencial deste novo "padrão de residências" que surge para suprir uma demanda desta "nova classe média": 
Figura 2: Novo empreendimento imobiliário em Queimados - RJ.

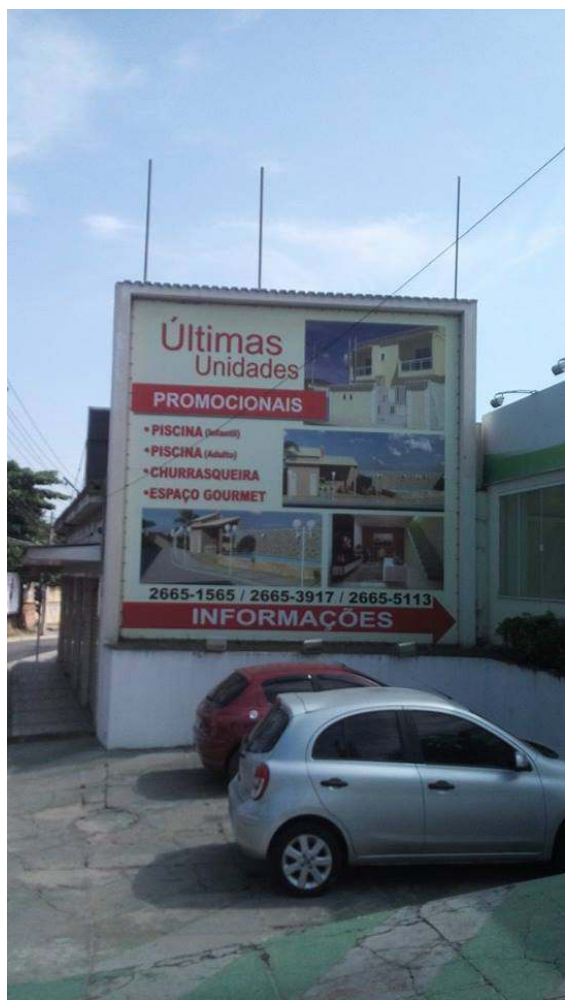

Fonte: Acervo do autor, 2015

Figura 3: Novo empreendimento imobiliário em Queimados - RJ.

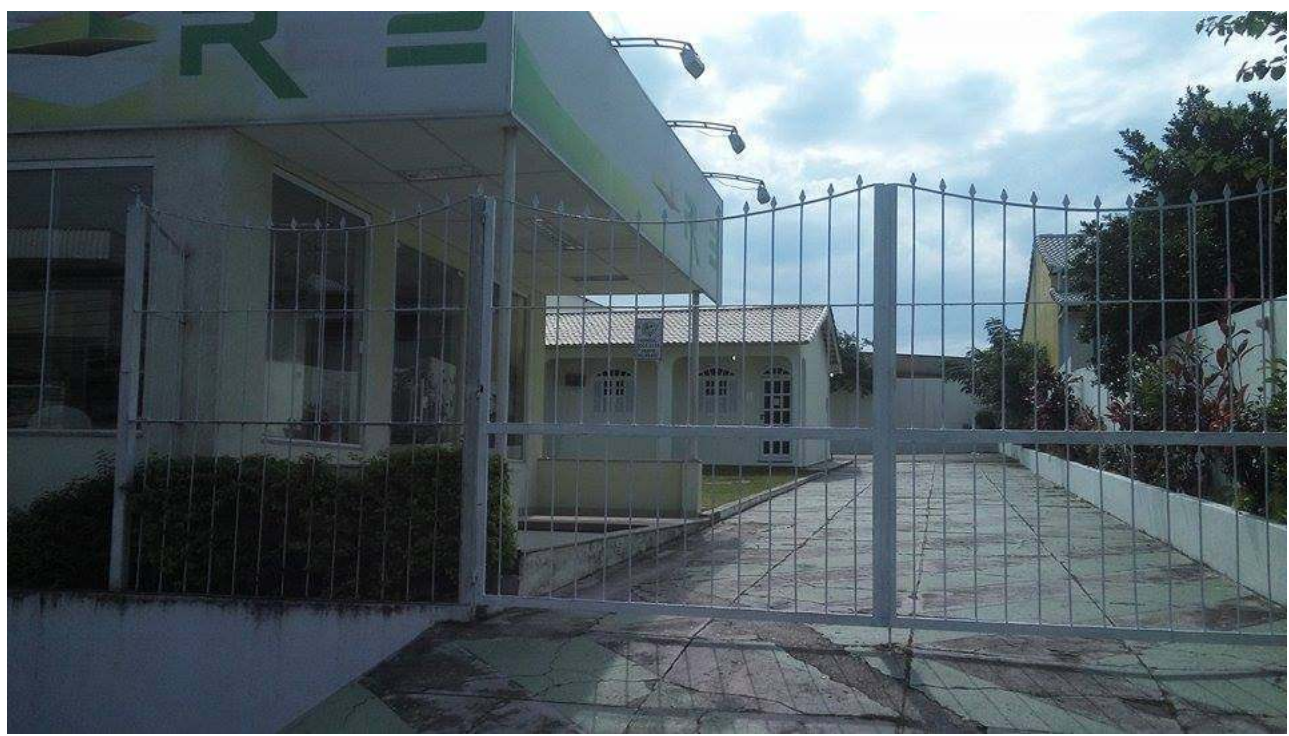

Fonte: Acervo do autor, 2015

Estes novos empreendimentos imobiliários, ilustrados em exemplos como nas figuras $2 \mathrm{e}$ 3 , surgem para suprir uma demanda mais qualificada por moradia. A periferia dos loteamentos populares e da autoconstrução assiste a chegada de imóveis residenciais com quartos de empregadas, suítes e três ou quatro quartos, compondo um padrão bem diferente do de grande parte da cidade. 

centro comercial. Uma obra em andamento, que já teve a primeira etapa concluída centro comercial. Una obra em an receu recursos do Banco Mundial, foi fruto da capacidade "empreendedora" do atual prefeito e mobilizou muitos esforços e recursos da prefeitura. Um centro comercial suntuoso e um calçadão arborizado compõe uma paisagem que serve de "propaganda" para o novo momento da cidade, onde é perceptível a "tentativa promover a imagem da cidade através do culto ao urbanismo de espetáculo" (HARVEY, 2010, p. 96).

Essa diferença entre o novo centro requalificado e que atrai empreendimentos comerciais e imobiliários de médio e alto padrão e o restante do município ainda carente de infraestrutura e concentrando grande parte dos estratos de renda de classe baixa ( $\mathrm{C} 1, \mathrm{C} 2 \mathrm{e}$ C3) nos convida a refletir sobre a cidade que emerge deste processo de reestruturação. Araújo (2011, p. 5), ao analisar as práticas urbanas empreendedoras, define que neste modelo de cidade "o importante mesmo é vender a beleza das áreas que rendem lucros e manter as áreas territoriais desprivilegiadas na maior passividade possível, de preferência escondidas" (ARAÚJO, 2011, p. 5).

Soja (1988, p. 193-194) define a reestruturação como um processo conflituoso, uma disputa entre o "velho e o novo", uma "intensificação de lutas competitivas pelo controle das forças que configuram a vida material". Sposito (2004) também reitera essa característica conflituosa do processo de estruturação e desestruturação do espaço urbano.

O surgimento destes novos "espaços de consumo" elitizados suprimiu, por exemplo, o espaço destinado aos camelôs e "comerciantes informais"; a prefeitura já informou ${ }^{10}$ que na segunda etapa da reforma os camelôs e comerciantes restantes que ainda estão presentes no centro da cidade serão alojados em outras localidades mais distantes. Ou seja, o "desenvolvimento" não se faz sem conflitos e sem ferir interesses daqueles que não fazem parte do "projeto modernizador".

Nota-se, portanto, um dos traços fundamentais da reestruturação urbana: a complexificação da estrutura urbana, que gera "o aparecimento de 'periferias' no centro e "centralidade na periferia" (SPOSITO, 2004, p. 305). O resultado desta "renovação urbana" pode ser conferido a seguir nas fotos (Figuras 6, 7, 8 e 9), registradas no centro da cidade.

Espaço e Economia, 8 | 2016 
Figura 4. Fachada do Centro comercial e calçadão após "requalificação"

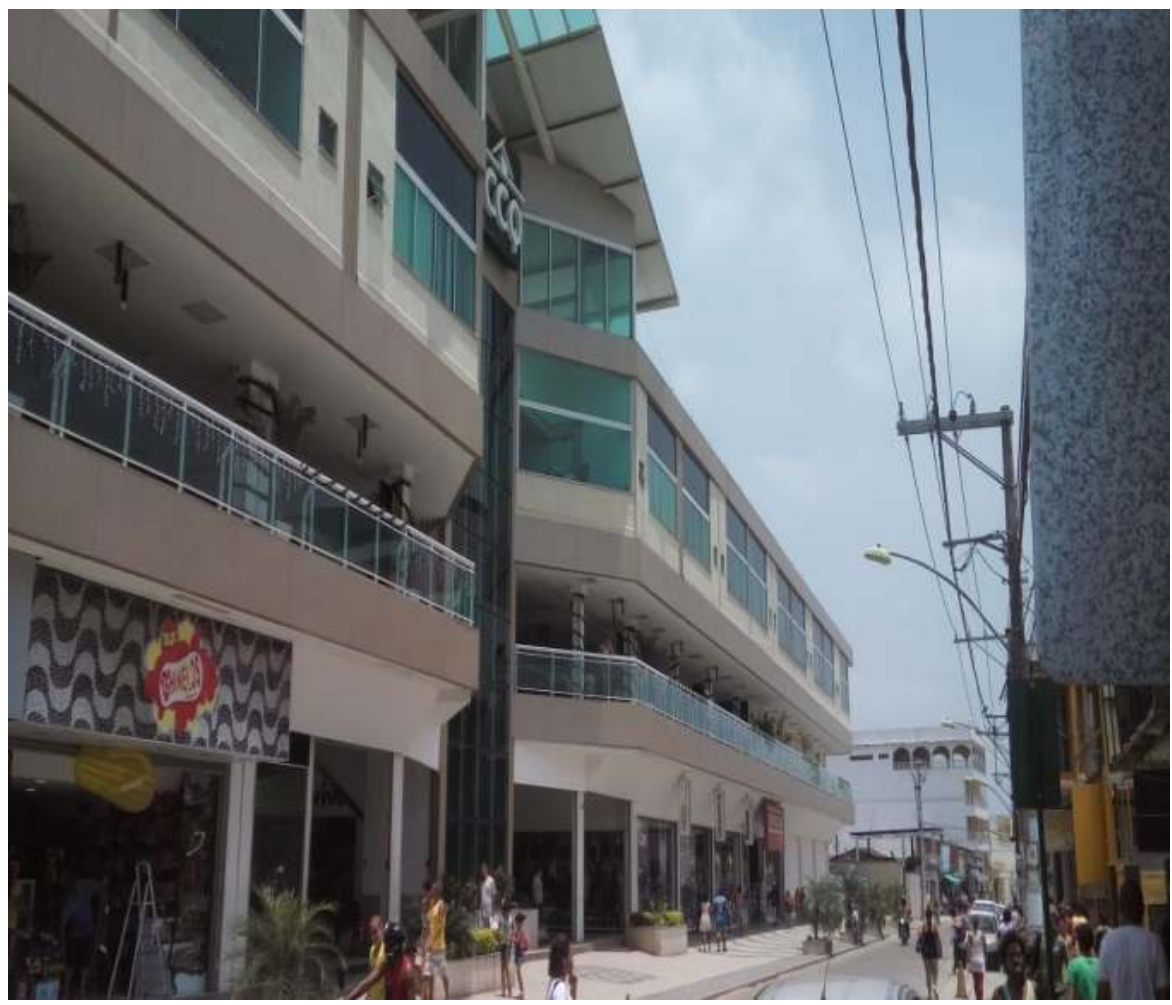

Fonte: Acervo do Autor, 2015.

Figura 5. Fachada do Centro comercial e calçadão após "requalificação"

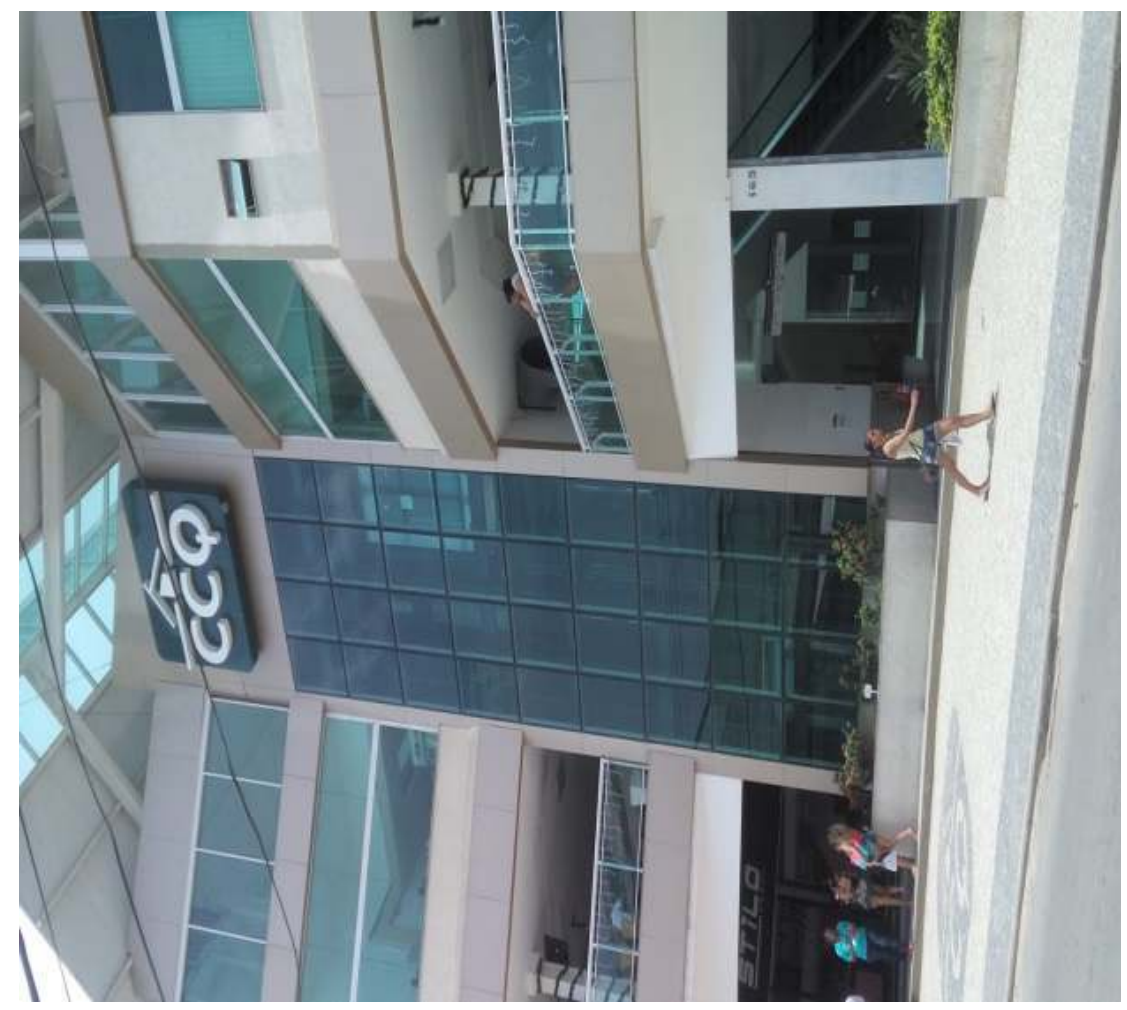

Fonte: Acervo do Autor, 2015. 
Figura 6. Fachada do Centro comercial e calçadão após "requalificação"

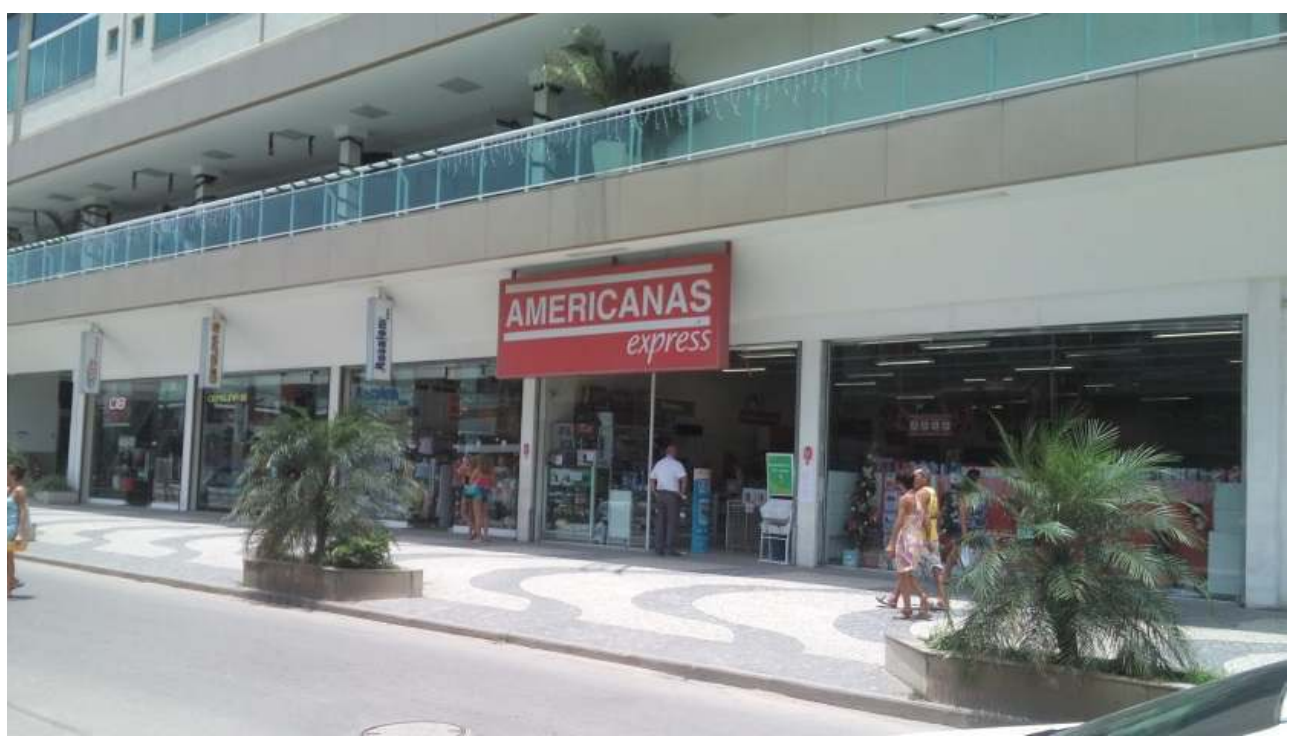

Fonte: Acervo do Autor, 2015

Figura 7 - Novos espaços de consumo: 'Megastore'.

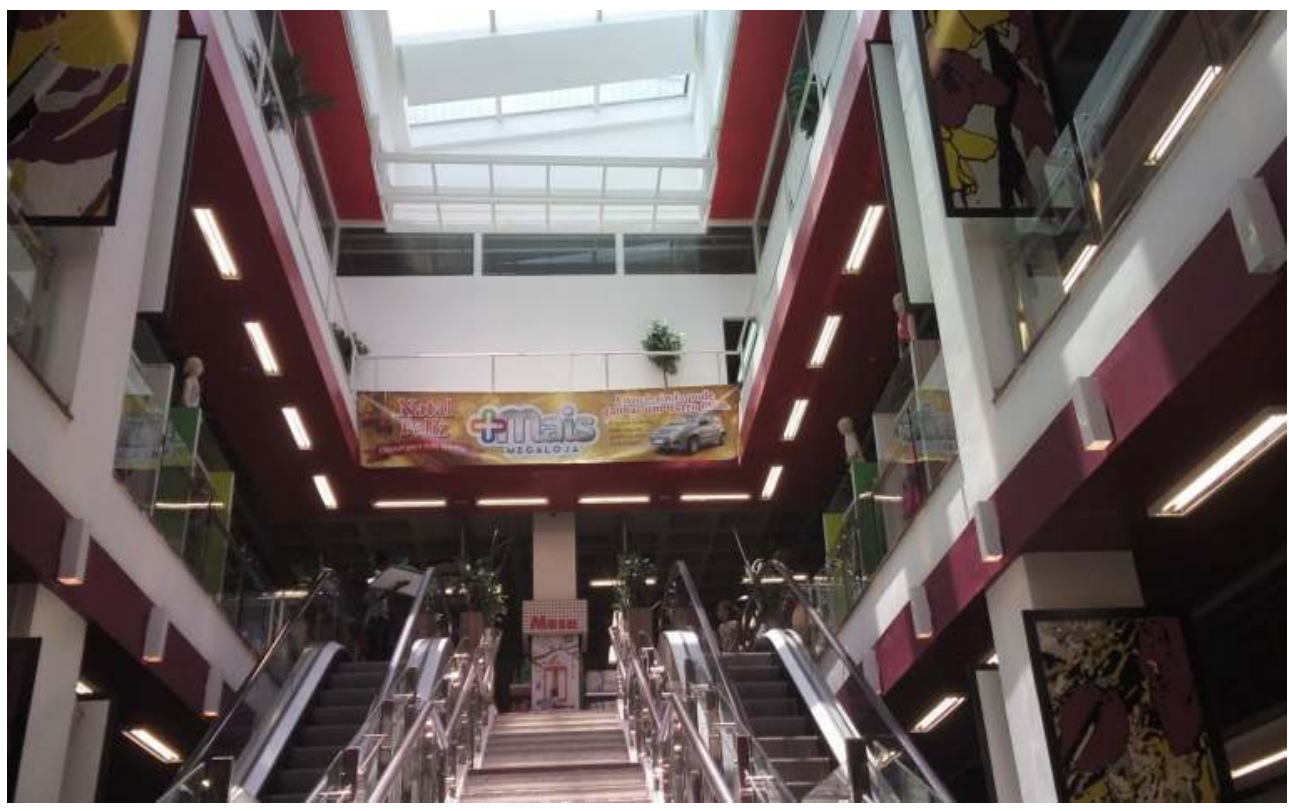

Fonte: Acervo do Autor, 2015.

Estes novos espaços são a materialização da "periferia que virou centro" (LAGO, 2007) e evidenciam as mudanças significativas ocorridas em Queimados e, consequentemente, na Baixada Fluminense nos últimos anos. Todas estas transformações nos indicam o desmoronamento, na realidade local, de categorias como "cidades dormitórios" e de termos como "periferia marginalizada". Da mesma maneira, tais modificações fazem emergir outros sentidos para a região que paulatinamente se transforma no eixo de desenvolvimento econômico e industrial do Estado do Rio de Janeiro, produzindo novos 
espaços mais heterogêneos e complexificando nosso entendimento da categoria periferia, exigindo um intenso esforço teórico e empírico para dar conta desta nova realidade.

\section{A chegada de novos agentes econômicos: as grandes redes e franquias ${ }^{11}$}

A "explosão" das franquias nos últimos anos ${ }^{12}$ resulta da necessidade constante do capitalismo de acelerar o tempo de giro de capital, e criar novas demandas e novos nichos de mercado para atender sua crescente produtividade. Ao possuir um sistema verticalizado de gerenciamento e de marketing, explorando o potencial e o fascínio que as grandes marcas exercem na população ${ }^{13}$ as franquias facilitam a organização do varejo (já que o franqueado compra uma estrutura organizacional "pronta") em distintas cidades, contudo, ao mesmo tempo "drenam" grande parte do lucro dos pequenos varejistas para os franqueadores (donos do direito de concessão da marca).

As transformações na esfera produtiva, que consolidaram a periferia metropolitana como o "lugar de trabalho" criaram condições para a chegada de novos agentes econômicos como as grandes redes varejistas e as franquias. A Baixada agora emerge também como um "lugar de consumo". As transformações urbanas recentes reforçaram a centralidade do centro comercial e criaram um espaço onde as novas camadas sociais emergentes podem frequentar e consumir.

Em um levantamento inicial no centro comercial identificamos franquias como Óticas Carol (investimento inicial necessário entre $\mathrm{R} \$ 250$ e $\mathrm{R} \$ 430$ mil), Cacau Show (investimento inicial em torno de R\$100 mil), Bob's (Investimento inicial de aproximadamente $\mathrm{R} \$ 700$ mil), O Boticário (investimento inicial a partir de $\mathrm{R} \$ 250 \mathrm{mil}$ ) e Subway (investimento inicial estimado em $\mathrm{R} \$ 250 \mathrm{mil}^{14}{ }^{14}$, dentre muitas outras ${ }^{15}$

O surgimento destes novos agentes econômicos na Baixada Fluminense é um interessante indicador do processo de reestruturação em curso na região, afinal

a consideração da centralidade urbana como critério para instalação da empresa - a

franquia - é fundamental na maximização do lucro, por isso a busca do target e do ponto comercial são ações prioritárias e racionalmente instituídas na lógica operacional dessas empresas, o que, por sua vez, possibilita a identificação de um consumidor específico (PORTO-SALES, 2014, p. 81).

41 A partir da segunda metade do século XX com a exportação do "american way of life", a América Latina, devido ao seu enorme contingente populacional e potencial mercado consumidor, se tornou atrativa para a chegada de grandes redes e de marcas de renome (PORTO-SALES, 2014). Entretanto, em um primeiro momento, esses agentes econômicos se concentravam nas grandes áreas urbanizadas dos adensamentos populacionais das regiões metropolitanas, pois buscavam "centros com alta demanda, centralidade e circulação" (KLAFKE, 2015, p. 965). Entretanto, o processo de descentralização industrial e a expansão dos investimentos produtivos na periferia metropolitana criaram não somente uma demanda pelo consumo, mas, por meio dos projetos de renovação urbana e criação de centros comerciais, ofereceu uma estrutura adequada para a chegada destes investimentos.

O aumento no número de empregos formais representa uma "estabilidade do consumo", atributo muito procurado pelas franquias ao definirem sua localização, Podemos observar 
na Tabela 3 como Queimados tem um crescimento muito significativo neste indicador, expressando um aumento de importância da cidade:

Tabela 3: Baixada Fluminense - Número de empregos formais - 2007 - 2012

\begin{tabular}{|c|c|c|c|c|c|c|c|}
\hline \multirow{2}{*}{$\begin{array}{lr}\text { Regiões } & \text { de } \\
\text { Governo } & \text { e } \\
\text { municípios } & \end{array}$} & \multicolumn{5}{|c|}{ Empregos formais } & \multirow[b]{2}{*}{2012} & \\
\hline & 2007 & 2008 & 2009 & 2010 & 2011 & & \\
\hline Estado & 3.665 .846 & 3.712 .383 & 3.851 .259 & 4.080 .082 & 4.349 .052 & 4.461 .706 & $22 \%$ \\
\hline $\begin{array}{l}\text { Região } \\
\text { Metropolitana }\end{array}$ & 2.837 .798 & 2.869 .136 & 2.984 .437 & 3.151 .210 & 3.345.357 & 3.447.709 & $21 \%$ \\
\hline Rio de Janeiro & 2.174 .568 & 2.161 .698 & 2.231 .333 & 2.348 .611 & 2.497 .662 & 2.572 .044 & $18 \%$ \\
\hline Belford Roxo & 24.747 & 28.354 & 28.347 & 30.772 & 31.212 & 32.597 & $32 \%$ \\
\hline Duque de Caxias & 136.768 & 147.908 & 159.488 & 173.958 & 180.873 & 172.989 & $26 \%$ \\
\hline Japeri & 4.211 & 3.634 & 4.881 & 5.434 & 5.459 & 6.014 & $43 \%$ \\
\hline Mesquita & 11.157 & 12.761 & 12.945 & 13.855 & 15.895 & 15.689 & $41 \%$ \\
\hline Nilópolis & 17.230 & 16.692 & 18.916 & 18.348 & 19.218 & 19.483 & $13 \%$ \\
\hline Nova Iguaçu & 84.169 & 83.736 & 86.721 & 93.779 & 98.111 & 100.771 & $20 \%$ \\
\hline Queimados & 10.148 & 9.858 & 12.337 & 14.144 & 17.020 & 26.209 & $158 \%$ \\
\hline São João do Meriti & 45.331 & 47.348 & 51.002 & 55.690 & 57.741 & 58.166 & $28 \%$ \\
\hline
\end{tabular}

Fonte: Fundação Ceperj, 2013. (Organização própria)

Em termos percentuais, o crescimento é de 158\% - o maior da Baixada Fluminense - e em termos absolutos surgiram 16.061 novos empregos formais, ou seja, um mercado consumidor considerável foi criado. Podemos definir, portanto, que a cidade atingiu "a quantidade mínima necessária de critérios, como infraestrutura, para se manifestar como centro de consumo lucrativos a empresas que têm a marca como principal ativo" ( PORTO-SALES, 2014, p. 88).

\section{Considerações finais}

44 A partir da década de [19]90, a confluência de vários fatores reestrutura significativamente a região da Baixada Fluminense. Este é um período de várias transformações, dentre as quais podemos enumerar:

1. Fragmentação de Nova Iguaçu, através de emancipações de vários municípios (Japeri, 1991; Queimados, 1991; Belford Roxo, 1993 e Mesquita, 1999), explicadas para Simões (2006, p.24) pela demanda que perpassava três fatores fundamentais: a busca pela identidade, por uma representatividade e a questão econômica; 
2. A chegada de investimentos industriais e a retomada do crescimento econômico fluminense, sendo que a expansão industrial para a Baixada "redefine o papel de cidades anteriormente secundárias" (OLIVEIRA, 2009, p.9);

3. Uma ruptura na estrutura social homogênea, geralmente identificada com uma formação típica da periferia, observável em algumas cidades - mais consolidada em Nova Iguaçu - que implicou na consolidação de um núcleo elitizado e a formação de uma "classe média" com uma maior poder aquisitivo, além do desenvolvimento de centralidades para além da capital carioca, já que novos espaços de consumo "mais qualificados" surgiram nestes espaços.

Todas estas transformações nos conduzem a algumas questões essenciais: até onde a antiga explicação baseada na relação centro-periferia composta por um "núcleo metropolitano hipertrofiado" (ABREU, 2013) e uma periferia carente de infraestrutura pode ser utilizada para explicar a realidade atual na região metropolitana fluminense? Será que estamos diante de uma transformação estrutural nesta relação entre metrópole e seu entorno ou a categoria periferia é apenas ressignificada?

Nossa hipótese é a de que ainda que esta incipiente "descentralização industrial" crie algumas subcentralidades, altere o papel de alguns municípios na divisão territorial do trabalho e crie uma "classe média" com poder de consumo mais elevado, isto não rompe estruturalmente com o modelo centralizado da metrópole fluminense. Afinal, por mais que o PIB Industrial do município do Rio de Janeiro - que em 1999 era responsável por 42,8\% do PIB industrial fluminense, número que se reduziu para 19,63\% em 2011 (CEPERJ, 2013) - a capital ainda continua sendo um centro financeiro e de gestão. Por exemplo, no ano de 2012, 80\% das aplicações de crédito de todo o estado foram realizados na cidade do Rio de Janeiro, bem como $78 \%$ dos depósitos à vista do setor privado. É possível ainda destacar: a capital fluminense possui em seu território 1171 agências bancárias de um total de 1966 do estado do Rio de Janeiro (CEPERJ, 2013). São dados que não devem ser desconsiderados.

Dessa forma, a perda de unidades fabris não representa uma alteração hierárquica na relação centro-periferia, mas na verdade uma transformação oriunda da reestruturação produtiva que tem como característica fundamental a "distinção entre o peri-produtivo à montante e à jusante" e a "oposição entre a indústria dos espaços metropolitanos e aquela das regiões periféricas" (FISCHER, 2009). Isto é, a separação entre gestão e produção, que implica na "fragmentação dos processos de trabalho" (CHESNAIS, 1996) e permite que as empresas possam usufruir das vantagens de se permanecer em uma concentração metropolitana ao mesmo tempo em que se utilizam dos grandes terrenos e da mão-deobra barata das regiões periféricas. Em um levantamento inicial, identificamos que das vinte e três (23) empresas instaladas no Distrito Industrial de Queimados, dezesseis (16) possuem o escritório administrativo na cidade do Rio de Janeiro ou em São Paulo, enquanto o restante são empresas de origem internacional.

51 Evidentemente, diferentes escalas e distintos processos interagem remodelando a geografia da cidade de Queimados e da Baixada Fluminense. Neste sentido, a década de 1990 marca uma transição significativa, onde os investimentos industriais transformam o papel desta cidade recém-emancipada na divisão territorial do trabalho metropolitano e transforma a estrutura urbana da cidade, que se adequa a este novo momento. 


\section{BIBLIOGRAPHY}

ABREU, Mauricio de Almeida. Evolução urbana do Rio de Janeiro. Rio de Janeiro: Editora IPP, 2013.

ARAÚJO, Flávia. Empresariamento Urbano: concepção, estratégias e críticas. In: Anais do I circuito de debates acadêmicos. Ipea. [Rio de Janeiro, 2011]. Disponível em: <http://www.ipea.gov.br/ code2011/chamada2011/pdf/area7/area7-artigo7.pdf> Acesso em fev. 2015.

BARRETO, Lima. Clara dos Anjos, $2^{a}$ ed. Editora Escala, s/a.

CASTELLS, Manuel. o debate sobre a teoria do espaço (cap. 3) In: A questão urbana. Rio de Janeiro: Paz e Terra, 1983, p.145 a 294.

CEPERJ. Anuario Estatistitico Fluminense 2013. Disponivel em: <www.fundacaoceperj.br> Acesso em ago. 2015.

CHESNAIS, François. A mundialização do capital. São Paulo: Xamã, 1996.

CORREA, Roberto Lobato. O Espaço Urbano. $1^{\text {a }}$ Ed. Rio de Janeiro: Editora Ática, 1989.

FISCHER, André. Indústria, ordenamento do território e transportes. $1^{\mathrm{a}}$ ed. São Paulo: Expressão Popular, 2009.

FURLANETTO et al. Promoção imobiliária e espaço residencial da classe média na periferia metropolitana do Rio de Janeiro. In: Revista Brasileira de Geografia, no 49 v. 2, 1987.

HARVEY, David. Do gerenciamento ao empresariamento: a transformação da administração urbana no capitalismo tardio. Revista Espaço e Debates, nº 39, 1996, p. 48-64.

HENRIQUE, Nilson, COSTA, Claudia Patrícia. Queimados: Imagens de uma cidade em construção. $1^{\text {a }}$ Ed. Queimados: Asamih, 2014.

IBGE. Censo Demográfico 2010. Disponível em: <www.ibge.gov.br> Acesso em: 10 fev. 2014.

JACOB, Cesar Romero; HEES, Dora Rodrigues; WANIEZ Philippe. Atlas das condições de vida na Região metropolitana do Rio de Janeiro. Rio de Janeiro: Editora PUC-rio, 2014.

KLAFKE, Karlise. As ações das franquias na produção do espaço urbano de pequenas cidades. In: Anais do XI Encontro Nacional da ANPEGE. Presidente Prudente/SP, 2015. p. 965-975 - cd-room.

LAGO, Luciana Corrêa. A "periferia" metropolitana como lugar do trabalho: da cidade-dormitório à cidade plena. In: Cadernos IPPUR/UFRJ/Instituto de Pesquisa e Planejamento Urbano e Regional da Universidade Federal do Rio de Janeiro. Ano XXI, no 2, p. 9 - 28, ago-dez 2007.

MARICATO, Erminia. Conhecer para resolver a cidade ilegal. Disponível em: http://www.usp.br/ fau/depprojeto/labhab/biblioteca/textos/maricato_conhecercidadeilegal.pdf >, s/a. Acesso em dez. 2015.

MINISTÉRIO DO TRABALHO E EMPREGO. Perfil econômico dos municípios. Disponível em <http:// bi.mte.gov.br/bgcaged/caged_perfil_municipio/index.php>. Acesso em fev. 2015.

OLIVEIRA, Leandro Dias; ROCHA, André Santos da. As novas dinâmicas produtivas em curso na Baixada Fluminense: breves apontamentos sobre uma nova geografia da Indústria. In: Revista Pilares da História. Ano11, edição especial, p.7-13, maio de 2010. 
OLIVEIRA, Leandro Dias; ROCHA, André Santos da. Desenvolvimento, reestruturação produtiva e conomia espacial: o processo de reordenamento Territorial no oeste metropolitano fluminense. Apresentado em: XIII Simpósio Brasileiro de Geografia Urbana. Disponível em: Anais... UERJ, Rio de Janeiro, 2013.

OLIVEIRA, Floriano José Godinho. Desconcentração industrial e espaço urbano/metropolitano: análise territorial da expansão metropolitana e da formação de novos eixos econômicos produtivo no rio de janeiro. 2009. Apresentado em: XIII encontro da associação nacional de pós-graduação e pesquisa em planejamento urbano e regional. Disponível em <http://www.anpur.org.br/revista/rbeur/ index.php/anais/article/view/3288> acesso em fev. 2015

OLIVEIRA, Alberto; RODRIGUES, Adrianno, O. Industrialização na periferia da Região Metropolitana do Rio de Janeiro: Novos paradigmas para velhos problemas. In: Semestre Econômico . Volume 12 no 24. pp. 127-143, Medelin, Colômbia, outubro de 2009. Disponível em: http:// revistas.udem.edu.co/ojs/index.php/economico/article/view/287/270. Acesso em ago. 2015.

PAGANOTO, Faber Araújo. Mobilidade espacial da população e mercado imobiliário na periferia metropolitana: a expansão dos condomínios fechados em nova Iguaçu/RJ. 184f. Tese (Doutorado em Geografia) - Programa de Pós Graduação em Geografia, Instituto de Geociências - CCMN, Rio de Janeiro, 2014.

PEREIRA, Regina, Celi. Estado, território e reestruturação produtiva na metrópole fluminense. In: Espaço e Economia. Volume: 3, Ano 2, Número 3. Rio de Janeiro, dezembro de 2013. Disponível em: < http://espacoeconomia.revues.org/390> acesso em set. 2015.

PORTO-SALES, Andréa Leandra. A Situação Espacial de Franquias na América do Sul: morfologia e centralidade urbanas em cidades médias da Argentina, Brasil e Chile. 281f. Tese (Doutorado em Geografia) - Faculdade de Ciências e Tecnologia, Universidade Estadual Paulista. Presidente Prudente, 2014.

PREFEITURA DE QUEIMADOS. Arquiteto e urbanista visita Queimados para desenvolver projeto de requalificação do centro do município [Rio de Janeiro, 2014] Disponível em: < http:// www.queimados.rj.gov.br/print.asp?id=1075> Acesso em ago. 2015.

SILVA, Adriana Carvalho. A leitura urbana de Lima Barreto em Clara dos Anjos. In: Espaço e cultura. UERJ, Rio de Janeiro, N. 25, P. 7-16, JAN./JUN. DE 2009.

SILVA, Robson Dias. Indústria e Desenvolvimento Regional no Rio de Janeiro. Rio de Janeiro. Editora FGV, 2012.

SIMÕES, Manoel Ricardo. A cidade Estilhaçada - Reestruturação Econômica e Emancipações Municipais na Baixada Fluminense. 2006. 290f. Tese (Doutorado em Geografia) - Departamento de Geografia do Instituto de Geociências da Universidade Federal Fluminense, 2006.

SIMÕES, Manoel Ricardo. Ambiente e Sociedade na Baixada Fluminense. Mesquita: Entorno, 2011.

SOJA, Edward. Geografias pós-modernas: A reafirmação do espaço na teoria social crítica. Rio de Janeiro: Jorge Zahar, 1993.

SPOSITO, Maria Encarnação Beltrão. Reestruturação das cidades (cap. 5). In: 0 chão em pedaços: urbanização, economia e cidades. Presidente Prudente: UNESP/FCT, 2004 [tese de livre docência], p.261 a 319 . 


\section{NOTES}

1. O livro 'Clara dos Anjos' foi escrito por Lima Barreto em 1922 e publicado postumamente somente em 1948; retrata a história da filha de um carteiro, morador do subúrbio carioca que se envolve com um "malandro" de origem social "mais nobre" acostumado a se aproveitar de jovens incautas. Lima Barreto foi um dos primeiros grandes nomes da literatura brasileira a tratar da paisagem da periferia carioca; descrever e narrar o cotidiano do subúrbio carioca fez parte de sua essência literária, afinal era "morador do próprio subúrbio, de família humilde e que se dizia vítima do preconceito racial e lamentava não ver reconhecidas sua formação intelectual e capacidade produtiva" (SILVA, 2009, p. 9-10).

2. No último censo do IBGE (2010), Queimados foi classificada como uma localidade $100 \%$ urbana e segundo o levantamento do MTE (Ministério do Trabalho e Emprego) havia somente três estabelecimentos agropecuários cadastrados empregando 17 pessoas no período de 2008 a 2015, enquanto que no mesmo período 4970 pessoas foram admitidas no setor industrial.

3. Informação oferecida pelo prefeito em entrevista concedida ao Jornal Extra do dia 25 de novembro de 2015 - "Edição Especial: 25 anos da emancipação".

4. Em um levantamento inicial realizado durante uma ida a campo, identificamos a presença de grandes redes de lojas varejistas como: Lojas Americanas, Casa \& Vídeo, Leader Magazine, Lojas Cem e franquias como Subway, Bob's, Cacau Show, dentre outras. Em uma comparação com imagens antigas do "Google Street View" percebemos que grande parte destes empreendimentos chega à cidade durante os anos de 2011 e 2012.

5. Utilizamos neste trabalho da concepção de "Baixada Reduzida", definida por Simões (2006), que compreende os municípios originados da fragmentação da cidade de Nova Iguaçu: Belford Roxo, Duque de Caxias, Japeri, Mesquita, Nilópolis, Nova Iguaçu, Queimados e São João do Meriti.

6. No ano de 2005 existiam 1631 professores registrando trabalhando na rede pública de ensino (fundamental e médio), enquanto em 2012 este número se reduziu para 1555 (IBGE Cidades, s/a). O IDHM de educação (Índice de Desenvolvimento Humano Municipal) da cidade era de 0,589 no ano de 2010, abaixo da média nacional que era 0,637.

7. Depois da cidade do Rio de Janeiro, Nova Iguaçu é o município que mais recebe migrações pendulares na Baixada, sua área de influência é bem significativa: "Nova Iguaçu, por sua vez, é o principal destino dos migrantes pendulares residentes em Queimados, Mesquita, Japeri, Nilópolis e Paracambi. 0 município de Nova Iguaçu tem considerável influência ainda sobre Belford Roxo, São João de Meriti e Seropédica, além de ser o terceiro principal destino dos deslocamentos pendulares originados no núcleo de metrópole" (PAGANOTO, 2014, p.67)

8. A diferenças de classes ( 2 a 3) (mais de 3) em um ano e (2 a 5) (mais de 5) em outro ano se devem a diferenças relacionadas a amostra de dados disponibilizadas pelo IBGE.

9. Site de busca Zap Imóveis - disponível em www.zapimoveis.com.br , busca realizada no dia 01, dez. 2015.

10. Comerciantes informais de Queimados podem ganhar novos pontos de trabalho. [Rio de Janeiro, 2013] Disponível em: <http://www.queimados.rj.gov.br/noticias_publicacao.asp?idArea=5\&idn=496> acesso em fev. 2014. - "O Prefeito de Queimados, Max Lemos, recebeu a direção da Supervia para iniciar os estudos de remodelação da Estação Ferroviária do Município, visando colocar o comércio informal da cidade nos espaços da empresa responsável pelos trens urbanos do Estado do Rio de Janeiro.(...) De acordo com o diretor da Supervia, Luiz de Souza, a empresa está elaborando um estudo para remodelação da Estação Ferroviária de Queimados.

11. Porto-Sales (2014) define que a franquia, é a representação da capacidade criativa e veloz de acumulação de capital por meio do consumo dirigido. Empresas organizadas pela lógica operacional do sistema de franquias apropriam-se de condições espaciais específicas para 
assegurar o sucesso da marca e a venda dos seus produtos que, por sua vez, já representam per se a necessidade de segmentação dentro de um dado ramo para gerar rentabilidade. Na América do Sul, essa modalidade de organização empresarial tem crescido exponencialmente no setor varejista, as chamadas franquias empresariais: hoje, são mais de 200.000 unidades de franquias. A lógica operacional - técnica e financeira - que caracteriza o sistema de franquias conforma uma base material, que revela a lógica territorial que lhe é inerente: a da busca pela centralidade.

12. Segundo Klafke (2015), as franquias têm expandido sua ação por todo o território nacional. Segundo estudos da Associação Brasileira de Franchising (ABF), as franquias ampliaram sua ação no Brasil tanto em número de franqueadoras, quanto em unidades franqueadas. Houve, conforme a $\mathrm{ABF}$, o crescimento no número de franqueadoras em 2014 de $8,8 \%$ em relação a 2013, contando com 2.942 redes, já com relação as unidades franqueadas, houve um aumento de $9,8 \%$, com o total de 125.641 unidades. Destaca-se ainda, conforme o estudo, que 70,8\% das redes do Brasil estão no Sudeste e 52,6\% no estado de São Paulo, quanto as unidades franqueadas, refere-se a $58,8 \%$ no Sudeste e $37,5 \%$ no estado de São Paulo.

13. Em uma conversa informal com uma moradora de um município da Baixada, nos foi relatado o grande impacto simbólico que existe no cotidiano dos moradores quando uma grande marca associada aos grandes centros do núcleo metropolitano se estabelece no local. O consenso de que "o progresso chegou, agora podemos comprar coisas de marca também como o pessoal do Rio de Janeiro".

14. O valor estimado de custo para abrir uma franquia foi retirado de: http:// fotos.estadao.com.br/galerias/fotos-pme,confira-40-franquias-que-exigem-investimento-der-27-mil-a-r-4-milhoes,23086?startSlide=0\&f=0. Acesso em: 20 de dezembro de 2015.

15. No primeiro trabalho de campo encontramos as seguintes grandes redes de lojas e franquias: Ponto Frio, Casas Bahia, Lojas Cem, Marisa, Leader, Cacau Show, Drogarias Pacheco, Citycol, Di Santini, Nalin, Quebra Vento, Subway, Lojas Americanas, Óticas Carol, CNA, Chicnelos, South\&Cia, Farmelhor, CBS, 4Feel, Fábrica de Bolos, Espelho Mágico, Maria Tocaia, Boticário (2 lojas), Ortobom (2 lojas), Bob's, Casa e Vídeo e Wizard. Em uma comparação realizada através das imagens do Google Maps de 2010/2011 percebemos que grande parte das lojas chegou após a requalificação do centro comercial recém-finalizada.

\section{ABSTRACTS}

Este artigo analisa como a chegada de investimentos industriais na periferia da região metropolitana impacta na produção do espaço urbano. Por meio do município de Queimados-RJ, o objetivo é entender o processo de reestruturação urbana em curso, que transforma antigas cidades-dormitórios em lugares de trabalho e de consumo.

This article analyses the impact of new industrial investments on the urban space production in Queimados - Rio de Janeiro and the transformation of old dormitory towns in new places of work and consumption.

Cet article analyse l'impact d'investissements industriels sur la production de l'espace urbain à la périphérie de la région métropolitaine de Rio de Janeiro. A travers de la municipalité de Queimados, on veut comprendre l'actuel processus de restructuration urbaine, capable de remplacer des anciennes villes-dortoirs par des espaces de travail et de consomation. 
En este artículo se analiza el impacto de las nuevas inversiones industriales en la producción del espacio urbano en Queimados - Río de Janeiro y la transformación de las antiguas ciudades dormitorio en nuevos lugares de trabajo y el consumo.

\section{INDEX}

Mots-clés: restructuration urbaine, région métropolitaine, centralité urbaine, Queimados, Baixada Fluminense.

Palavras-chave: reestruturação urbana, região metropolitana, centralidade urbana Keywords: Urban restructuring, metropolitan region, urban centrality, Baixada Fluminense, Queimados-RJ.

Palabras claves: Reestructuración urbana, región metropolitana, centralidad urbana, Queimados.

\section{AUTHOR}

\section{MARCELO LOURA DE MORAIS}

Mestrando em Geografia pelo Programa de Pós-Graduação em Geografia da UFRJ, Bolsista CAPES.

E-mail: marcelo_fjv@hotmail.com 